\title{
Implementation of graphical user interface to observe and examine the frequency and rotor angle stability of a power system due to small disturbances
}

\author{
Nur Ashida Salim¹, Mohamad Salehan Ab. Samah², Hasmaini Mohamad ${ }^{3}$, Zuhaila Mat Yasin ${ }^{4}$, \\ Nur Fadilah Ab Aziz ${ }^{5}$ \\ ${ }^{1,3,4}$ Faculty of Electrical Engineering, Universiti Teknologi MARA, Malaysia \\ ${ }^{2}$ ECO Special Waste Management, Singapore \\ ${ }^{5}$ Institute of Power Engineering, Electrical Power Department, College of Engineering, Universiti Tenaga Nasional, \\ Malaysia
}

\section{Article Info}

Article history:

Received May 4, 2019

Revised Jul 9, 2019

Accepted Jul 23, 2019

Keywords:

Graphical user interface

Long transmission line

Medium transmission line

Short transmission line

Transmission line model

\begin{abstract}
The aim of this research is to anticipate the stability status of a power system when the system is exposed to a change in frequency and rotor angle due to small disturbances. The proposed study was implemented on the IEEE Reliability Test System 1979 (IEEE RTS-79) which contains 24 buses, 38 transmission lines and 32 generators. Steady state stability limit of a system refers to the maximum amount of power that is permissible through the system without loss of its steady state stability. This research proposes the development of a Graphical User Interface (GUI) to observe the frequency and rotor angle stability due to the effect of small disturbances using the One Machine Infinite Bus (OMIB) technique. This proposed technique could ease the power system utility especially the power system operation to observe and examine the system frequency and rotor angle stability due to small disturbances. The findings from this research has proven that the proposed technique to observe the frequency and rotor angle stability due to small disturbances has successfully been developed using a GUI.
\end{abstract}

Copyright $@ 2020$ Institute of Advanced Engineering and Science. All rights reserved.

\section{Corresponding Author:}

Nur Ashida Salim,

Faculty of Electrical Engineering,

Universiti Teknologi MARA,

40450 Shah Alam, Selangor, Malaysia.

Email: nurashida606@salam.uitm.edu.my

\section{INTRODUCTION}

Power system stability is defined as the property of a power system that enables it to remain in the state of a normal operating condition maintaining a stable equilibrium or return to its original acceptable operating state after being subjected to a small or large disturbance [1-3]. For example, a sudden voltage drop due to load change can push the system to an instable state [4]. Power system stability is an important issue in grids when these systems are exposed to various severities of disturbances, such as a loss of generation or loads [5].

Transient stability is a crucial part of a power system operation [6,7]. The stability of a power system is its ability to create re-establishing powers proportionate to the disturbing forces to protect the state of equilibrium. In the case of the interconnection of large power networks, this power system stability problem will get worse. This research focuses on the ability of a power system to operate based on the frequency and rotor angle stability. By 2010, the proportion of electricity consumption to be covered by renewable energies was envisaged to rise to at least $12.5 \%$, and further down the line to at least $20 \%$ by 2020 . Preliminary studies foresee further significant increases in the timeframe extending to the year 2050 [8]. 
For synchronous generators (SGs), there exists a critical clearing time below which SG can retain a stable operation [9]. The critical clearing time (CCT) [9] for an induction generator is the maximum time for a fault to be cleared, within the time span that the induction generator can retain its stability [11]. This will not be so again after the absolute rotor angle controllers have been deployed throughout the power system [12]. The controller has an angle that can order the turbine valve or power electronic braking devices either to accelerate or decelerate the generator rotor. Then, it can return to its original position [13].

Thus, this paper proposes the development of a Graphical User Interface (GUI) to observe the rotor angle and frequency stability of a power system by using One Machine Infinite Bus (OMIB) and mathematical modelling. It will also examine the impact of small disturbances to the stability of a power system and to investigate the tendency of a power system to maintain the stability in frequency and rotor angle.

\section{RESEARCH METHOD}

Many countries worldwide have deregulated their electricity generation and distribution grid where the generation, transmission and distribution systems owned by different companies will result in serious competition among these companies in the electricity market in order to provide more reliable, efficient and cost effective electricity supply to the consumers [4]. The stability of an interconnected power system is the capability of the power system to return to a normal or stable operation after having been subjected to some type of disturbance. Stability considerations have been perceived as an essential part of power system planning for a long time. With interconnected systems consistently growing and stretching out over immense areas, it is becoming increasingly more difficult to keep different parts of a power system synchronised [5].

\subsection{Rotor Angle Stability}

Rotor angle stability [14] refers to the capability of synchronous machines in an interconnected power system to endure in synchronism after being subjected to a disturbance. Rotor angle stability is associated with the changes of active power flow that creates angular separation between synchronous machines in the system [8]. Rotor angle instability happen when the angular swings of several generators lead to their loss of synchronism. Therefore, the stability and form will be restored. There is then no devastation to the thermal system when the changing magnitude of the turbine valve is limited in the angle controller [9]. The following procedure explains the rotor angle stability calculations performed in this research [15].

$$
\begin{aligned}
& \delta=\left(\delta_{0}+\delta_{d}\right) \times \frac{180}{\pi} \\
& \delta_{0}=\sin ^{-1} \frac{P_{m}}{P_{\max }} \\
& \delta_{d}=x=\frac{\delta_{d 0}}{\sqrt{\left(1-z^{2}\right) \times e^{\left(-z \times \omega_{n} \times t\right) \times \sin \left(\omega_{d} \times t+\theta\right)}}} \\
& \delta_{d 0}=\alpha \times \frac{\pi}{180} \\
& \omega_{d}=\omega_{n} \times \sqrt{\left(1-z^{2}\right)} \\
& \omega_{n}=\sqrt{\frac{(\pi \times 60)}{\left(H \times P_{s}\right)}} \\
& \theta=\cos ^{-1}(z) \\
& z=\frac{D}{2} \times \sqrt{\frac{(\pi \times 60)}{\left(H \times P_{s}\right)}} \\
& P_{s}=P_{\max } \times \cos \left(\delta_{0}\right) \\
& t=0: 0.01: 3
\end{aligned}
$$

a) Calculate the performed power angle in degrees, $d$ using (1) where the $\delta_{o}$ and $\delta_{d}$ can be calculated using (2) and (3), respectively.

b) Determine the initial angle in radian, $\delta_{d o}$ from (4).

Implementation of Graphical User Interface to observe and examine the frequency ... (Nur Ashida Salim) 
c) Determine the damped frequency of oscillation, $w_{d}$ from (5) and determine the undamped frequency of oscillation, $w_{n}$ from (6), both values are then inserted into (3). $H$ is a constant where it is set to 9.92.

d) Calculate the value of the phase angle theta, $\theta$ from (7) and the value of damping ratio, $z$ using (8).

e) Determine the value of damping ratio, $z$ where $D$ is the angle of disturbance inserted by the user. The time, $t$ is set from 0 second to 3 minutes using a $0.01 \mathrm{~s}$ interval.

f) Determine the value of $P_{s}$ from (8) to be inserted into (6), (7) and (8).

\subsection{Frequency Stability}

Frequency stability is the ability of a power system to keep its frequency consistent following a severe system drag arising from a significant imbalance between generation and load [13]. A frequency instability prompts the tripping of a generating unit and/or load. The stability problem refers to the 608ehavior of the synchronous machines after being exposed to the disturbances. Frequency stability is the ability of a power system to keep up consistent to durable frequency in a serious system upset resulting in a serious imbalance between generation and load. Frequency instability will lead to the tripping of generating units and/or loads. Frequency stability has two types which is a short-term or long-term phenomenon. In addition, the controller of the rotor angle can curb an inter-area of a low frequency oscillation efficiency without any help from a remote signal [15]. More complex situations in which frequency instability is caused by steam turbine over speed controls or boiler/reactor protection and controls are longer-term phenomena with the time frame of interest ranging from tens of seconds to several minutes [17]. The following procedure explains the frequency stability calculations performed in this research [18].

$$
\begin{aligned}
& f=f_{0}+\frac{\delta \omega}{2 \Pi} \\
& f_{0}=50 \mathrm{~Hz} \\
& \delta_{\omega}=\frac{-\omega_{n} \delta_{d 0}}{\sqrt{\left(1-z^{2}\right) \exp \left(-z \omega_{n} t\right) \sin \left(\omega_{d} t\right)}}
\end{aligned}
$$

a. Calculate the frequency $\mathrm{f}$, in $\mathrm{Hz}$ using (11).

b. The value of fo is $50 \mathrm{~Hz}$ which is the frequency used in Malaysia.

c. After that, determine the initial angle in radian, Dd0 using (4). Determine the damped frequency oscillation, wd from (5), the undamped frequency of oscillation, wn from (6), and the value of damping ratio, z using (7).

d. Then, find $\delta \mathrm{w}$ using (13) to be inserted into (10).

e. Then all these values are inserted into (13).

f. Time, $\mathrm{t}$ is from 0 second to 3 minutes within the interval of $0.01 \mathrm{~s}$.

\subsection{One Machine Infinite Bus (OMIB)}

It has become one of the major requirements for an interconnected system to perform Transient Stability Analysis (TSA) to ensure that the system is working safely without any violation to the generator stability during faults. TSA is a part of operational planning where it highlights the ability of a system to oppose severe disruption whilst ensuring continuity of services.

The computational challenges of a multi-machine system can be minimised by simplifying the original state scale system to a dynamic equivalent model. The simplest dynamic equivalent model of a multi-machine system can be obtained by means of the One Machine Infinite Bus. The essential features of a system can be retained by applying the concept of Single Machine Equivalent (SIME).

SIME is a direct method which is derived from the equal angle criterion combined with the timedomain stability program that transforms the multi-machine power system into an OMIB system [19].

\subsection{Graphical User Interface (GUI)}

GUI is a crucial aspect when it comes to observing. It is a main connection between the end-user and the device, so it is crucial to be well presented with an easy learning concept [20] to provide the best user experience [21]. GUI is selected because it is easier and user friendly, which makes it suitable for study.

From Figure 1, the overall process of the GUI is shown. First, the GUI starts when the user runs or opens the GUI application. The main page of the screen acts as user input data. Prior to that, the user needs to open the selection of faulted bus and trip line. When the user clicks on this button, another tab of GUI will open that allows the user to choose the faulted bus. After marking the line to be selected as the faulted bus, 
the user inserts their input data into the GUI. Next, the user clicks the "Run" button to start the evaluation. The user needs to wait until the evaluation is finished. The evaluation is finished when the graph is plotted.

After the evaluation, the user can see the output which the settling time is. This settling time is the time required for an output to reach and remain within a given error band following some input stimulus. This time is dependent on the bus, damping ratio and small disturbance inserted. The user can see the plotted data both in frequency stability and rotor angle stability at the main page. To select another faulted line, the user can reopen the selection bus by clicking the selection button. The process can then be repeated for any other faulted bus as listed in the selection.

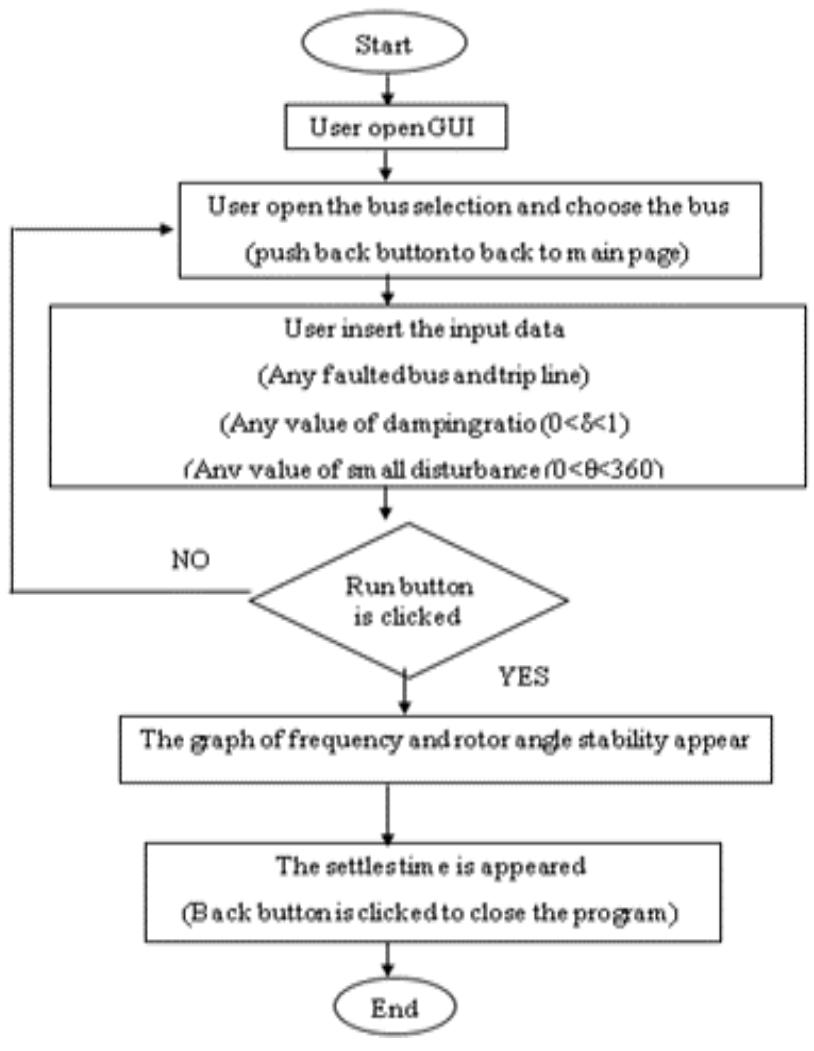

Figure 1. Flowchart of the overall proposed GUI

\subsection{Execute the Graphical User Interface (GUI)}

Firstly, the user needs to click on the "Run" button to open the GUI main page. As can be seen in Figure 2, there are input, output, and selected faulted bus and trip line for the user to insert the data. Then, the user needs to click on the selected faulted bus and trip line to choose the bus.

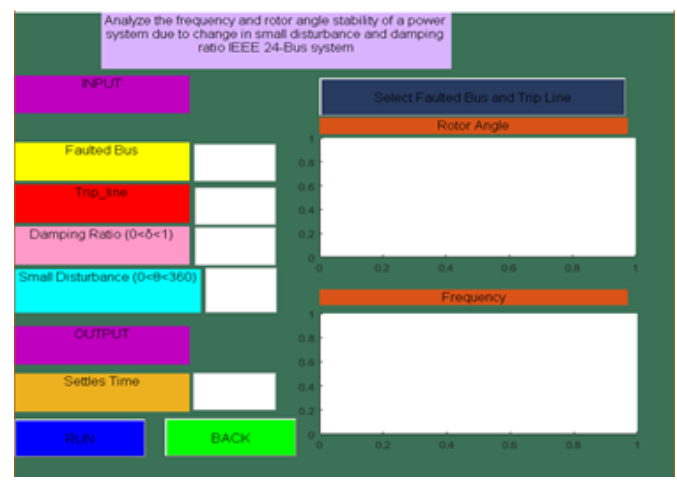

Figure 2. First page of GUI

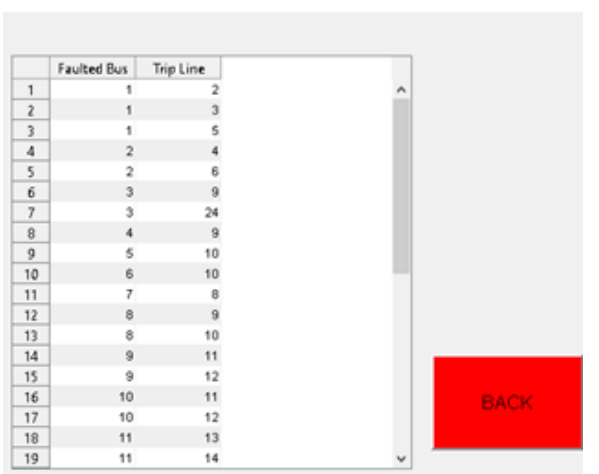

Figure 3. Selection of Faulted Bus

Implementation of Graphical User Interface to observe and examine the frequency ... (Nur Ashida Salim) 
Then, the user will see there is a table of faulted bus and trip lines as shown in Figure 3 which represent the IEEE RTS-79 transmission line data. There are 38 transmission lines which the user can choose to execute the analysis. There will be an error if the user chooses other than the listed lines. Then, the back button needs to be clicked to return to the GUI main page.

\subsection{Insert Data}

Insert data as shown in Figure 4. There will be four inputs that the user needs to insert which are faulted bus, trip line, damping ratio, and small disturbance. The value of damping ratio must be in the range of $0<\delta<1$ and the small disturbance is in the range of $0<\theta<360$. Then, the user will click the "RUN" button to start the simulation.

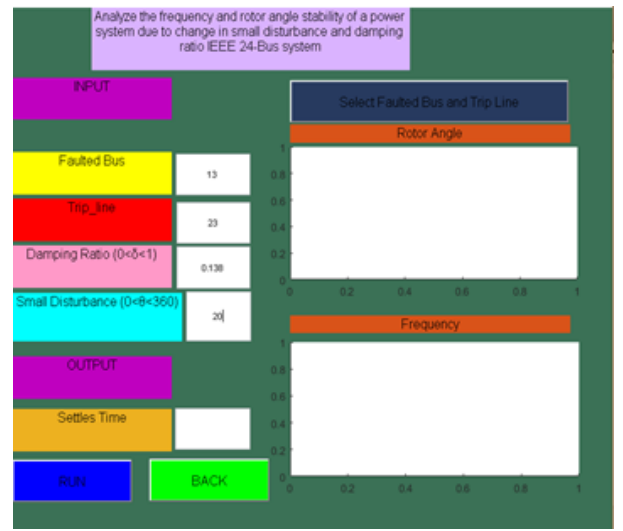

Figure 4. User insert the input

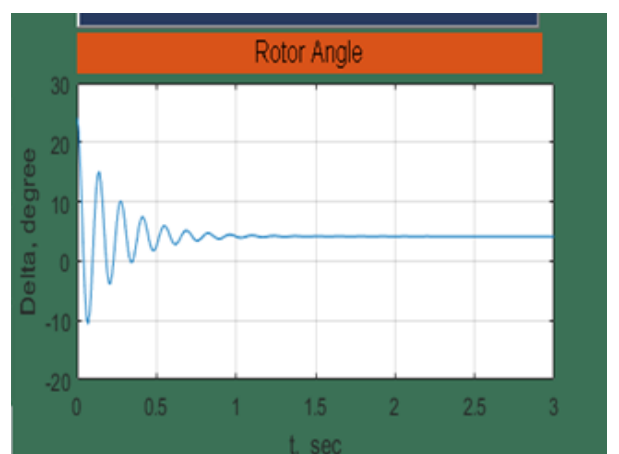

Figure 5. Output of Rotor angle stability

\subsection{Data collection}

From the program, there will be three outputs that need to be examined. Figure 5 shows the results of rotor angle stability. Figure 6 shows the data of frequency stability and Figure 7 is the output of settling time.

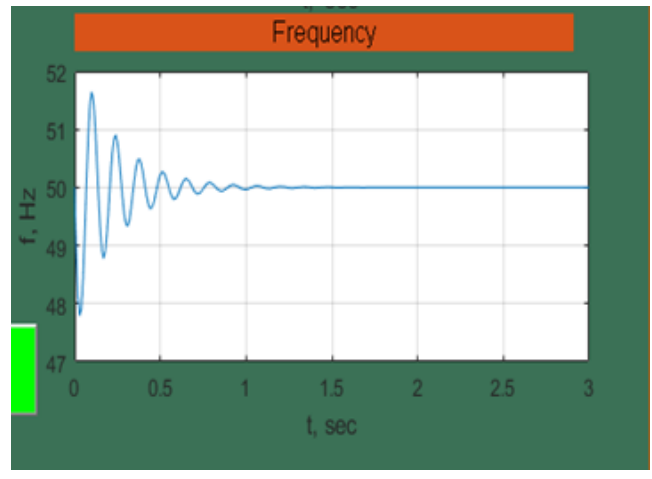

Figure 6. Output of Frequency stability

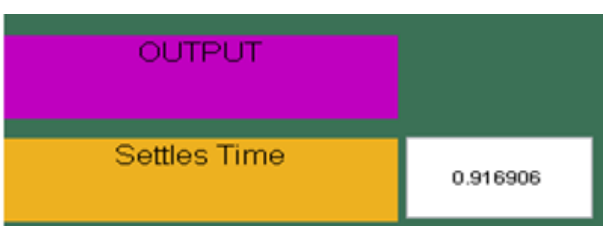

Figure 7. The output (Settling time)

\section{RESULTS AND DISCUSSION}

The steady-state stability refers to the capability of a power system to remain in synchronism when dealing with small disturbances $[22,23]$. The motion of the system is free, and stability assured if the system returns to its original state. In this analysis, six types of results will be discussed.

\subsection{Data Analysis}

From the program of transient stability, the results of rotor angle stability and frequency stability can be seen from Figure 5 and Figure 6, respectively. From these results, all the precautions can be made. 


\subsubsection{Damping Ratio $=\mathbf{0 . 1 3 8}$, Disturbance $=100$}

Figure 8 shows the user selected 0.138 for the damping ratio, -100 for disturbance as the data, faulted bus is 13 , and trip line bus is 13-23. The response shows that a small disturbance will be followed by a relatively slowly damped oscillation of the rotor before steady state operation at synchronous speed is continued. The highest rotor angle is $14.15324^{\circ}$ and the lowest rotor angle is $-3.24414^{\circ}$. The Malaysian utility frequency required for the system to remain stable is at $\pm 10 \%$ from $50 \mathrm{~Hz}$. From Figure 8 , the highest frequency is $50.82085 \mathrm{~Hz}$ and lowest frequency is $48.89733 \mathrm{~Hz}$. Therefore, for the case study of damping ratio equal to 0.138 and the angle of disturbance of 100 , the system can stabilise within $0.916906 \mathrm{~s}$.

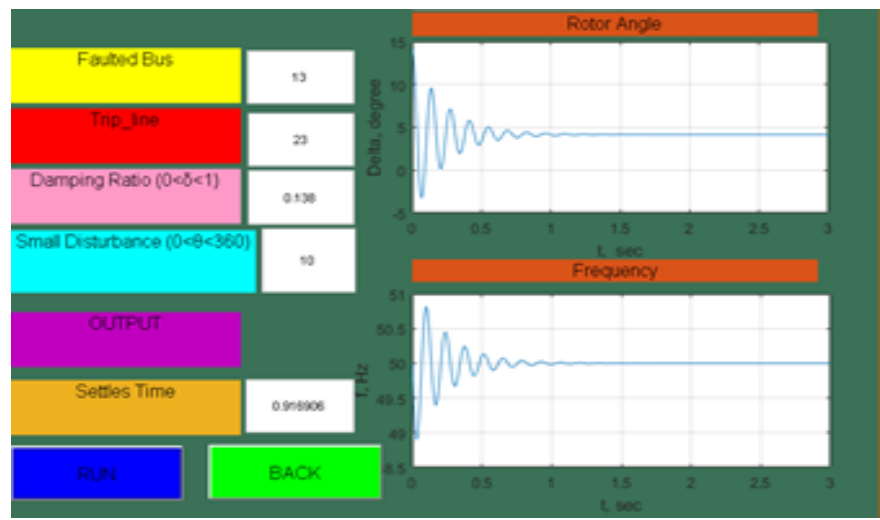

Figure 8. Damping Ratio $=0.138$, Disturbance $=10 \mathrm{o}$

\subsubsection{Damping Ratio $=\mathbf{0 . 1 3 8}$, Disturbance $=190 \mathrm{o}$}

Figure 9 shows the user selected 0.138 for the damping ratio, -1900 for disturbance as the data, faulted bus is 13 , and trip line bus is $13-23$. The response shows that a small disturbance will be succeeded by a relatively slowly damped oscillation of the rotor before steady state operation at synchronous speed is continued. The highest rotor angle is $194.153235^{\circ}$ and the lowest rotor angle is $-136.3969^{\circ}$. The Malaysian utility frequency required for the system to remain stable is at $\pm 10 \%$ from $50 \mathrm{~Hz}$. From Figure 9 , the highest frequency is $64.3153 \mathrm{~Hz}$ and lowest frequency is $29.04928 \mathrm{~Hz}$. Therefore, for the case study of damping ratio equal to 0.138 and the angle of disturbance of 1900 , the system can stabilise within $0.916906 \mathrm{~s}$.

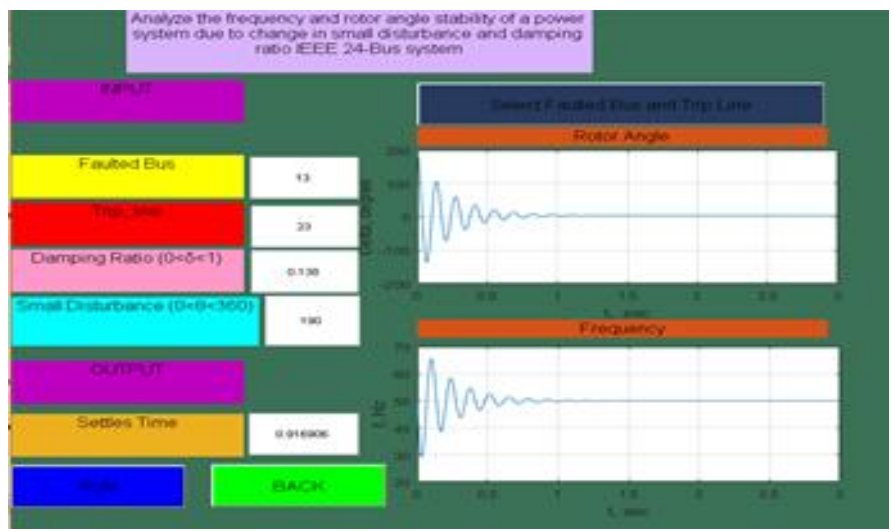

Figure 9. Damping Ratio $=0.138$, Disturbance $=190 \mathrm{o}$

\subsubsection{Damping ratio $=0.570$, Disturbance $=100$}

Figure 10 shows the user selected 0.570 for the damping ratio, -100 for disturbance as the data, faulted bus is 13, and trip line bus is 13-23. The response shows that a small disturbance will be followed by a relatively slowly damped oscillation of the rotor before steady state operation at synchronous speed is continued. This is because of the effect of high damping ratio. The highest rotor angle is $14.153235^{\circ}$ and the lowest rotor angle is $1.6157889^{\circ}$. The Malaysian utility frequency required for the system to remain stable is

Implementation of Graphical User Interface to observe and examine the frequency ... (Nur Ashida Salim) 
at $\pm 10 \%$ from $50 \mathrm{~Hz}$. From Figure 10, the highest frequency is $50.1907776 \mathrm{~Hz}$ and lowest frequency is $49.228718 \mathrm{~Hz}$. Therefore, for the case study of damping ratio equal to 0.570 and the angle of disturbance of 100 , the system can stabilise within 0.221988 s. The time is shorter because of the effect of high damping ratio.

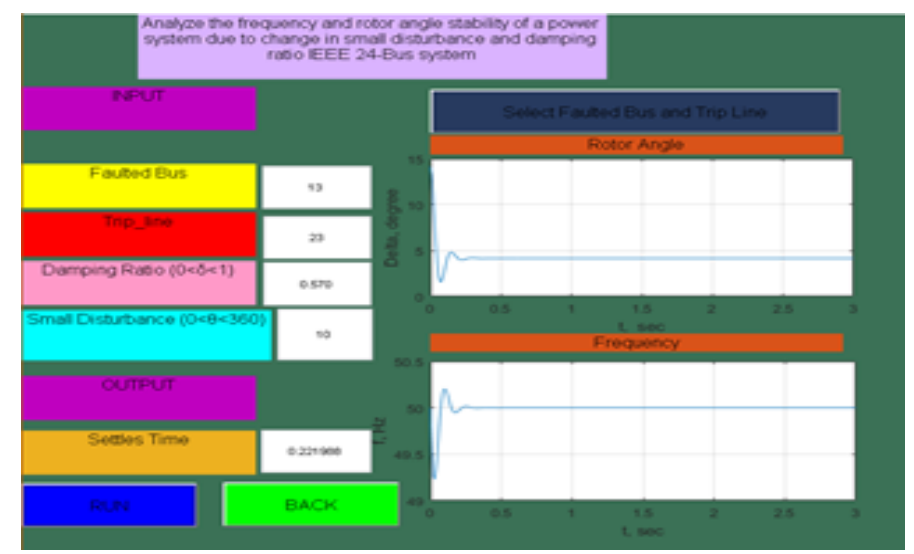

Figure 10. Damping Ratio = 0.570, Small Disturbance $=10 \mathrm{o}$

\subsubsection{Damping Ratio $=0.570$, Disturbance $=190 \mathrm{o}$}

Figure 11 shows the user selected 0.570 for the damping ratio, -1900 for disturbance as the data, faulted bus is 13 , and trip line bus is $13-23$. The response shows that a small disturbance will be succeeded by a relatively slowly damped oscillation of the rotor before steady state operation at synchronous speed is continued. This is because of the effect of high damping ratio. The highest rotor angle is $194.153235^{\circ}$ and the lowest rotor angle is $-44.05824^{\circ}$. The Malaysian utility frequency required for the system to remain stable is at $\pm 10 \%$ from $50 \mathrm{~Hz}$. From Figure 11, the highest frequency is $53.624774 \mathrm{~Hz}$ and lowest frequency is $35.34564 \mathrm{~Hz}$. Therefore, for the case study of damping ratio equal to 0.570 and the angle of disturbance of 100 , the system can stabilise within 0.221988 s. The time is shorter because of the effect of high damping ratio.

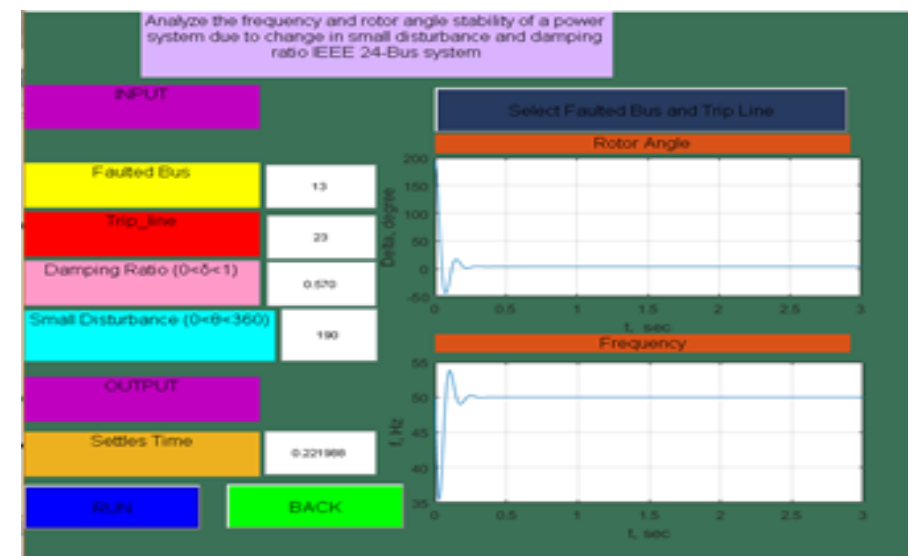

Figure 11. Damping Ratio $=0.570$, Disturbance $=190 \mathrm{o}$

\subsection{Rotor Angle and Frequency Stability}

From the results of the analyses above, the GUI managed to observe the rotor angle and frequency stability due to the different values of damping ratios and the angles of disturbance. From the graphs, with damping ratios close to zero, the settling times are slower compared to larger values of the damping ratio. This type of damping ratios within $0<\delta<1$ are termed underdamped. If the damping ratio is close to 0 , there are fluctuations in the system before it stabilises. A higher damping ratio value will stabilise a system 
faster. During normal operation of the generator, the rotor magnetic field and stator magnetic field rotate with the same speed. However, there will be an angular separation between the rotor magnetic field and stator magnetic field which depends on the electrical torque (power) output of the generator. This means there will be more overshoot on a system for the system to stabilise. In this analysis, the value of settling time will be increased and it will affect the system's stability. Frequency stability depends on equilibrium that will be restored between system generation and load demand with minimum loss of loads. Numerous reasons can lead to loss of system frequency stability, like loss of generation which may be a reaction to a sudden imbalance between system generation and load demand. Therefore, an instability of frequency refers to electrical power deficiency. Frequencies below $47 \mathrm{~Hz}$ will lead to damage of steam turbines, while hydro power plants and thermal units are more robust. Frequencies down to $45 \mathrm{~Hz}$ may result in the worst, which is disconnection [24].

\section{CONCLUSION}

This paper shows that the operation of a power system in steady state stability can be examined and observed by using a Graphical User Interface (GUI). GUI has been implemented in this project and validated on the IEEE RTS-79 bus system in order to examine power system stability due to the impact of system frequency and rotor angle. Power systems are always required to be in a normal and stable operation to operate normally at rated operating condition and required improvement in terms its stability. It is the responsibility of transmission system operators to ensure that the system frequency is in the allowable limit in order to provide an efficient reserve generation. Based on the findings from this research, the generator frequency is more stable if the damping ratio is large and the angle of disturbance is small. In addition, the generator rotor angle is said to be stable if the damping ratio is larger and the angle of disturbance is greater. Thus, the power system utility can predict the stability of the system due to changes in damping ratio and disturbance [25].

\section{ACKNOWLEDGEMENTS}

The authors would like to thank the Faculty of Electrical Engineering and Research Management Institute (RMI), Universiti Teknologi MARA, Malaysia, and the Ministry of Higher Education (MOHE), Malaysia, through research grant 600-IRMI/FRGS 5/3 (157/2019) for the financial support of this research.

\section{REFERENCES}

[1] Qi Wang, Feng Li, Yi Tang, Yan Xu, "Integrating Model-driven and Data-driven Methods for Power System Frequency Stability Assessment and Control”, IEEE Transactions on Power Systems, 2019.

[2] T.R. Ayodele, A.A. Jimoh, J.L Munda, J.T Agee, "Challenges of Grid Integration of Wind Power on Power System Grid Integrity: A Review”, vol. 2, no. 4, International Journal of Renewable Energy Research, 2012.

[3] Peng Wang, Zhenyuan Zhang, Qi Huang, Ni Wang, Xing Zhang, Wei-Jen Lee, "Improved Wind Farm Aggregated Modeling Method for Large-Scale Power System Stability Studies”, IEEE Transactions on Power Systems, 2018.

[4] T. Tamilarasi and P. G. Student, "Analysis of Impact on Rotor Angle Stability of DFIG Wind Turbines Employing STATCOM," 2016.

[5] B. S. Abdulraheem and C. K. Gan, "Power System Frequency Stability and Control: Survey," vol. 11, no. 8, pp. 5688-5695, 2016.

[6] Setiadi, H and Jones, KO (2016) Power system design using firefly algorithm for dynamic stability enhancement. Indonesian Journal of Electrical Engineering and Computer Science, 1 (3). pp. 446-455. ISSN 2502-4752

[7] Ali Hamzeh, Zakaria Al-Omari, Improved model for investigating transient stability in multimachine power systems, vol, 13, no. 1, Indonesian Journal of Electrical Engineering and Computer Science, 2019.

[8] I. Erlich, K. Rensch, and F. Shewarega, "Impact of Large Wind Power Generation on Frequency Stability," pp. 1-8, 2006.

[9] Prechanon Kumkratug, Investigating the Critical Clearing Time of Power System with the Exact Medium Transmission Line Model, vol. 9, no. 3, American Journal of Applied Sciences, 2012.

[10] Raja Masood Larik, Mohd.Wazir Mustafa, Manoj Kumar Panjwani, A statistical jacobian application for power system optimization of voltage stability, vol, 13, no. 1, Indonesian Journal of Electrical Engineering and Computer Science, 2019.

[11] T. Ananthapadmanabha, A. D. Kulkarni, M. Pujar, H. Pradeep, and S. Chetan, "Rotor angle stability analysis of a distributed generator connected to distribution network," Engineering, vol. 2, no. November, pp. 107-113, 2010.

[12] Nur Ashida Salim, Muhammad Murtadha Othman, Ismail Musirin, Mohd Salleh Serwan, Improvisation on Standard Limit of the Critical Clearing Time Specified for the Protection Relays Using One Machine Infinite Bus Equivalent, vol. 785, Applied Mechanics and Materials, 2015.

[13] D. K. Sambariya, S. Shringi, "Optimal design of pid controller for load frequency control using harmony search algorithm", Indonesian Journal of Electrical Engineering and Computer Science, vol. 5, no. 1, pp. 19-32, 2017. 
[14] Mirza Saric, Generator Dynamic Response Analysis and Improvement Following Distribution Network Disturbance, vol.7, no. 2, Indonesian Journal of Electrical Engineering and Computer Science, 2017.

[15] Nur Ashida Salim, Ahmad Asri Abd Samat, Muhammad Murtadha Othman, Hasmaini Mohamad, Nur Fadilah Ab Aziz, Nur Azzammudin Rahmat, "Implementation of GUI in the Determination of Critical Clearing Angle using the OMIB and Equal Area Criterion", J. Electrical Systems, 2018.

[16] Q. Wei, W. Guo, X. Han, T. Li, and M. Yang, "Analysis on the Effect of Rotor Angle Control for Transient Stability Enhancement," pp. 1-6, 2014.

[17] J. Yi, X. Zhou, and Y. Xiao, "Model of cascading failures in power systems," 2006 Int. Conf. Power Syst. Technol. POWERCON 2006, 2007.

[18] Nur Ashida Salim, Zuhaina Zakaria, Hasmaini Mohamad, Zuhaila Mat Yasin, Muhammad Ashri Ab Aziz, Development of graphical user interface to monitor the power system frequency stability due to cascading failure, 2017 3rd International Conference on Power Generation Systems and Renewable Energy Technologies (PGSRET), 2017.

[19] "Power System Stability 12.1," 1972.

[20] N. A. Salim, M. M. Othman, I. Musirin, and M. S. Serwan, "Risk assessment of cascading collapse considering the effect of hidden failure,” PECon 2012 - 2012 IEEE Int. Conf. Power Energy, no. December, pp. 778-783, 2012.

[21] Jian Ma, Vaithianathan Venkatasubramanian, Scott Feuerborn, Clifton Black, Mark Halpin, Shih-Min Hsu, A Software Suite for Power System Stability Monitoring Based on Synchrophasor Measurements, pp 449-476, Power System Grid Operation Using Synchrophasor Technology

[22] Sean McGuinness, Mahendra Patel, Adrian Kelly, "Performance of protection relays during stable and unstable power swings", vol. 2018, no. 15, The Journal of Engineering, 2018.

[23] Md. Shazzadul Islam and Muhammad Fayyaz Khan, "Stability Analysis of a Hybrid Power Plant: An Analysis through ETAP Software", International Journal of Engineering and Technology, Vol. 11, No. 2, April 2019

[24] Q. Wei, X. Han, W. Guo, M. Yang, and N. He, "The principle of absolute rotor angle control and its effect on suppressing inter-area low frequency oscillations," Int. J. Electr. Power Energy Syst., vol. 63, pp. 1039-1046, 2014.

[25] Hassan Haes Alhelou, Mohamad-Esmail Hamedani-Golshan, Reza Zamani, Ehsan Heydarian-Forushani and Pierluigi Siano, "Challenges and Opportunities of Load Frequency Control in Conventional, Modern and Future Smart Power Systems: A Comprehensive Review”, Energies, 2018. 